members, general information regarding the objects, scope and work of the Institute.

Any Member or Associate may obtain a copy upon application to the Secretary's office by mail or in person.

\section{Some Fundamental Principles of Power Plant Design *}

BY J. W. ESTERLINE

The accepted definition of an electrical power plant is that it is an aggregation of machinery and apparatus for converting the latent energy of some combustible or the potential energy of falling water into electrical energy. The engineer must keep in mind the fact that for every set of conditions there is a particular type of plant which, under those conditions, will return the largest dividends. . The most important conditions affecting the design of a power plant are: (1) The site; (2) the cost of soal; (3) water supply; (4) character of load; (5) capacity of the station. The site of a proposed plant is important because accessibility to a market for power often means lower investment cost and subsequent maintenance of transmission lines, and available sources of coal and water must always be large factors in the determination of a proper site. In congested districts where real estate is high the designer must keep within certain reasonable limits as to floor space to keep down investment costs. Coal prices determine largely the result of possible competition. Hydroelectric plants cannot compete with steam plants when coal prices fall much below $\$ 2.25$ per ton. On the other hand they are serious competitors if prices rise to $\$ 3.00$ and above. Water supply affects power plant design very largely both in hydroelectric and steam plants. Abundance of water supply is not alone sufficient. Certain localities possess water supplies favorable for hydroelectric plants but

*Abstract of address before the Purdue University Branch of the A. I. E. E. on November 9 , 1910. very adverse to steam plants because vegetable growths and chemical properties lead to annoying boiler and aondenser scale. Load characteristics determine machine types and initial investments. Lighting loads are heavy at night and usually very light during the day. Proper design to meet these conditions enables the installation to stand the peak at 100 per cent overload for a short time and carry the day load at about normal. Power loads, as railway and industrial, are comparatively regular and require therefore their own special apparatus. Load characteristics also affect the price at which power may be sold. Station capacity is of course dependent upon load characteristics and the possible increase in future market. Every plant should be designed to meet competition even though it does not exist, for the successful plant is one properly designed and engineered from the start. It has been said that efficiency does not always mean economy. Efficiency can be had under ideal conditions but these are obtained only by high investment and maintenance costs. The designer's object is to combine efficiency and economy so as to obtain the best plant. Comparatively few items vary with load conditions. These are coal, oil, waste, etc. Labor, maintenance and repairs, depreciation, interest, taxes, insurance, etc., are entirely independent of load conditions. Comparison of various types of plants shows that results are about equal but that first costs and fuel charges influence economical operation greatly. When one realizes that 25 or 30 per cent of power costs above investment charges is for fuel these facts impress him more. Gas engine plants cost more to install than steam engine plants and up to coal costs of $\$ 2.00$ per ton, the cheaper steam plant is a competitor but when coal prices are higher the results are reversed. Likewise the hydroelectric plant is a competitor of both gas engine and steam plants when coal is high but at lower prices results may be reversed. 